\title{
Evaluation of Survival Rate and Physicochemical Properties of Encapsulated Bacteria in Alginate and Resistant Starch in Mayonnaise Sauce
}

\section{Bigdelian $\mathrm{E}^{1}$ and Razavi $\mathrm{SH}^{2 *}$}

${ }^{1}$ Department of Food Science and Technology, Shahre kord Branch, Islamic Azad University, Shahre kord, Iran

${ }^{2}$ Department of Food Science and Technology, Faculty of Biosystem Engineering, Campus of Agriculture and Natural Resources, The University of Tehran, Tehran, Iran

\begin{abstract}
Three types of symbiotic mayonnaise sauces, with free, encapsulated bacteria with calcium alginate (in $4 \%$ concentration) and encapsulated with calcium alginate and resistant starch by two strains of $L$. acidophilus and $L$. case $i$ were manufactured in triplicate under the same conditions. The numbers of viable cells, $\mathrm{pH}$, acidity and rheological properties' of symbiotic mayonnaise samples during 91 days of storage in refrigerated $\left(4^{\circ} \mathrm{C}\right)$ conditions was evaluated. It was observed that the number of viable cells of Lactobacillus acidophilus and $L$. casei was reduced significantly $(p<0.05)$ from day 1 to day 91 of storage period in Free State comparing encapsulated bacteria in both type of them. Reduction of viable cells encapsulated with $\mathrm{Hi}$ maize-alginate had a slower rate than probiotic cells encapsulated with calcium alginate $(4 \%)$ in both $L$. acidophilus and $L$. casei mayonnaise samples container types. About changing in $\mathrm{pH}$ and increasing acidity of symbiotic mayonnaise sauces, the samples containing free probiotic cells had the highest changing and samples inoculated encapsulated cells with $\mathrm{Hi}$ maize-alginate mixture had lowest changing in these factors between all sample types. Also there weren't any significant changes in rheological properties of encapsulated symbiotic mayonnaise sample compared with control samples but in samples containing free cells a significant differences compared with control samples were seen. Finally, proved microencapsulation could help survival probiotic cells enough in therapeutic effects on consumers at the end of storage and modification encapsulation with adding $\mathrm{H}$ maize starch to calcium alginate improved preserving chemical qualities of symbiotic mayonnaise sauce.cells enough in therapeutic effects on consumers at the end of storage and modification encapsulation with adding Hi maize starch to calcium alginate improved preserving chemical qualities of symbiotic mayonnaise sauce.
\end{abstract}

Keywords: Calcium alginate; Resistant starch; Microencapsulation; Lactobacilli; Survival; Mayonnaise sauce

\section{Introduction}

The expansion of new food products turns out to be increasingly challenging, as it has to comply the consumers' expectations for products that are at once relish and healthy [1] , in this regard, functional food which have health benefits further than their nutritional contents and especially foods containing probiotics are products that are growing in popularity [2].

Probiotics are defined as alive microorganisms which, when employed in sufficient amounts confer a health benefit to the consumers. Prebiotics are non-digestible substances which provide a beneficial physiological effect on the host by selectively stimulating the favorable growth or activity of a limited number of indigenous bacteria [3]

On the protective level, probiotics can act as a 'barricade' against pathogens, by decreasing the luminal $\mathrm{pH}$, producing bacteriocins, competing for limiting nutrients, activate mucosal immune responses and by sticking to the intestinal mucosa, thereby occupying an ideal position at the expense of potentially harmful colonizers [4]. It has been suggested that they must be presented at a minimum level of $106 \mathrm{CFU} / \mathrm{g}$ of Probiotic products or $107 \mathrm{CFU} / \mathrm{g}$ at point of delivery or be consumed in adequate amounts to comply a daily intake of $108 \mathrm{CFU}$ [5].

Probiotics must be metabolically stable and active in the product, surviving while passing the upper digestive tract in large numbers, and showing the ability to adhere and colonize the intestine system [6]. The physical protection of probiotics by microencapsulation is a new method to improve the probiotic survival. Encapsulation helps to separate the bacterial cells from the effects of the harsh environment and gastrointestinal tract, thus potentially preventing cell from dead
[7]. The benefits of applying alginate as an encapsulating agent include: non-toxicity, formation of suitable matrices with calcium chloride to entrap sensitive materials such as living microbial cells, easiness in trapping living microbial cells and inexpensively [8].

Mandal, Puniya and Singh proved an increasing concentration of calcium alginate from $2 \%$ to $4 \%$ which had a positive effect on the survival of $L$. casei in simulated harsh conditions of GIT and heat processing, and calcium alginate in $4 \%$ concentration had the best effects [9].

The prebiotics, indigestible food components, affects the host by selectively instigating either the growth or activity, or both or a limited number of bacterial species already living in the colon [10]. A food product containing both probiotics and prebiotics is named as symbiotic or functional food. There is a synergy between probiotics and prebiotics in symbiotic products [11]. Combining alginate with starch as a prebiotic leads to better effectiveness of different bacterial cells specifically LAB. Also combination of calcium alginate with starch

*Corresponding author: Razavi SH, Department of Food Science and Technology, Faculty of Biosystem Engineering, Campus of Agriculture and Natural Resources, The University of Tehran, Tehran, Iran, Tel: 0098-2612248804,0098-912-2347367; E-mail: srazavi@ut.ac.i

Received May 26, 2014; Accepted June 28, 2014; Published July 08, 2014

Citation: Bigdelian E, Razavi SH (2014) Evaluation of Survival Rate and Physicochemical Properties of Encapsulated Bacteria in Alginate and Resistant Starch in Mayonnaise Sauce. J Bioprocess Biotech 4: 166 doi: 10.4172/21559821.1000166

Copyright: (c) 2014 Bigdelian E, et al. This is an open-access article distributed under the terms of the Creative Commons Attribution License, which permits unrestricted use, distribution, and reproduction in any medium, provided the original author and source are credited. 
produces beads with good unified structures and prebiotic effect of the bead shell [12].

Food, especially dairy products are Preferred as an ideal mean for delivering probiotic bacteria to the human gastrointestinal tract [13] but restriction of dairy products such as the presence of allergens and the need for cold storage facilities, as well as an increasing request for new foods and tastes have begun a trend in non-dairy probiotic product development. Further, it is important to expand probiotic products with food and drinks that are part of day to day normal diet to maintain minimum beneficial level easily [14]. An alternative strategy to increase the efficacy of a probiotic treatment would be to use a food matrix which naturally contains a higher content of ingredients with protective properties [4]. The development of novel formulations is a challenging task but, regardless of whether the product is newer improved, the product must be stable during storage and transportation, easy to handle and apply, enhance the activity of the organism in the field, be cost-effective and practical.

Mayonnaise is of course not only one of the most favored sauces but also apparently one of the oldest and most greatly used sauce in the today's world [15]. Mayonnaise is a kind of semi-solid, oilin-water emulsion. It is customarily prepared by carefully mixing egg yolk, vinegar, oil, and spices (especially mustard). Mayonnaise which made in this way typically contains $70-80 \%$ fat [16]. Physicochemical properties of food carriers used for probiotic delivery, such as buffering capacity and $\mathrm{pH}$, are important factors that affect survival of the probiotic and therefore potential probiotic effects during gastric passage. Food formulations with acceptable $\mathrm{pH}$ ranges and high buffering capacity would increase the $\mathrm{pH}$ of the gastric tract and thereby improve the stability of probiotics [17], so mayonnaise due to having some advantages like its high buffering capacity, similar $\mathrm{pH}$ to some dairy products and its good matrix to protect of probiotics (because of having a large amount of protective ingredients like oil \& egg) could be a new choice to produce a new functional food.

\section{Material and Method}

\section{Preparation and enumeration of free and encapsulated probiotics}

Pure freeze-dried probiotic culture of $L$. casei $(L c-01)$ and $L$. acidophilus (La5) were obtained from CHR-Hansen (Harsholm, Denmark) and were activated by inoculating in the MRS-broth (de Man-Rogasa-Sharpe) at $37^{\circ} \mathrm{C}$ for $24 \mathrm{~h}$. The probiotic biomass in late$\log$ phase was collected by centrifugation at $600 \mathrm{~g}$ for $10 \mathrm{~min}$ at $4^{\circ} \mathrm{C}$ (Microcentrifuges SIGMA; model 1-14K; Nr. 10021), then washed twice in sterile $0.9 \%$ saline under the same centrifugation conditions, and used in the microencapsulation process.

Bacterial counts were determined immediately after manufacturing of mayonnaise (at time 0 ) and during 91 days storage at $5^{\circ} \mathrm{C}$. The samples of mayonnaise $(10 \mathrm{~g})$ were diluted in $100 \mathrm{ml}$ sterile peptone water $(0.1 \%)$ and $1 \mathrm{ml}$ aliquot dilution was poured into plates of the MRS agar [18-20].

Counting of probiotic bacteria was achieved as described by Haynes and Playne [21]. All container of mayonnaise was sampled on each week of enumeration. All enumerating plates of $L$. casei and $L$. acidophilus were incubated at $37^{\circ} \mathrm{C}$ for $72 \mathrm{~h}$ under aerobic conditions. The averages of all results were expressed as colony-forming units per gram of sample (CFU/g). To count the encapsulated bacteria in mayonnaise, the entrapped bacteria were released from the beads according to the method of Sheu and Marshall [22]. Ten grams of mayonnaise were re- suspended in $100 \mathrm{~mL}$ of phosphate buffer (0.1 M, pH 7.0), followed by shaking in a stomacher for $10 \mathrm{~min}$. The mayonnaise sample containing free bacteria was treated in a similar way, in order to maintain the same treatment conditions. The counts (CFU/g) were determined by plating on MRS-agar as discussed above. The mayonnaise sample containing free bacteria was treated in a similar way so as to maintain the same treatment conditions. All experiments were done in triplicate.

\section{Microencapsulation procedure}

All glassware's and solutions used in the protocols were sterilized at $121^{\circ} \mathrm{C}$ for $15 \mathrm{~min}$. Alginate beads were produced using a modified encapsulation method originally reported by Sheu and Marshall [22]. All treatments including a Sodium alginate solution 4\% (Merck, Darmstadt, Germany) and a $2 \%$ alginate mixture in distilled water containing 2\% Hi-maize resistant starch (Sigma, Aldrich, Germany) were prepared, sterilized by autoclaving $\left(120^{\circ} \mathrm{C}\right.$ for $\left.15 \mathrm{~min}\right)$ and cooled to $38-40^{\circ} \mathrm{C}$. Twenty milliliters of this solution and $4 \mathrm{~mL}$ of cell suspension were transferred into a centrifuge tube $(40 \mathrm{~mL})$ and the content was vortexed to homogeneity. Soybean oil $(100 \mathrm{~mL})$ containing $0.2 \%$ Tween 80 (emulsifier) was taken in a beaker $(500 \mathrm{~mL})$ and to this the alginate-cell mixture was added drop wise while stirring magnetically. After $5 \mathrm{~min}$, a uniformly turbid emulsion was obtained to which $0.1 \mathrm{M}$ calcium chloride $(100 \mathrm{~mL})$ was quickly added for hardening of microcapsules and breaking the emulsion. The capsules were harvested by centrifuging at $350 \mathrm{~g}$ for $10 \mathrm{~min}$ at $41^{\circ} \mathrm{C}$ and washed twice with distilled water. The long-term activity of BL21_MlrA in comparison with wild Sphingomonas strain confirmed much higher potential of the modified bacteria. Immobilization in alginate allowed forming beads with high activity toward MC. A column packed with alginate entrapped cells eliminated MC efficiently from contaminated freshwater. These promising results will broaden the perspective of practical application of microorganisms in bioremediation of freshwater.

\section{Production of mayonnaise sauce}

All ingredients used to prepare the mayonnaise, such as soybean oil, eggs, vinegar, mustard, sugar, and salt were purchased from the local supermarket. mayonnaise recipe was modified from Chen [23] with the following ingredients in percentage $(\mathrm{w} / \mathrm{w})$ : pure whole egg (yolk + albumen) $14 \%$, vinegar (5\% (w/v) acetic acid) $9 \%$, soybean oil $74 \%$, salt $1.0 \%$, vanillin $0.1 \%$, mustard $0.54 \%$, sugar $1.0 \%$ and ground white pepper $0.36 \%$ [23].

The preparation was as follows: firstly egg and vinegar were mixed together and then all other ingredients except oil were added and stirred homogeneously by a mechanical overhead stirrer. Finally oil was added very slowly, while stirring at $1600 \mathrm{rpm}$ for $1 \mathrm{~min}$, followed by $2000 \mathrm{rpm}$ for another $4 \mathrm{~min}$. The mixture was cooled to $5-10^{\circ} \mathrm{C}$ and stored [16] The mayonnaise was divided to six parts of $250 \mathrm{~g}$ (A, B, C, D, E and F). $1 \%(\mathrm{w} / \mathrm{v})$ free L. casei and L. acidophilus were added to batches $A$ and $\mathrm{B}$, respectively. The initial counts of these bacteria in mayonnaise for $\mathrm{A}$ and $\mathrm{B}$ were about $6 \times 10^{9}$ and $5 \times 10^{8}(\mathrm{CFU} / \mathrm{g})$, respectively and $\mathrm{D}$ portions of mayonnaise sauce mixed with freshly prepared encapsulated L. casei and L. acidophilus into $4 \%$ calcium alginate beads. The initial counts of these bacteria for $\mathrm{C}$ and $\mathrm{D}$ were about $3 \times 10^{8}$ and $3 \times 10^{9}$ (CFU/g), respectively. Also, microencapsulated bacteria L. casei and $L$. acidophilus into beads containing $2 \%$ calcium alginate and $2 \% \mathrm{Hi}$ maize starch incorporated into $\mathrm{E}$ and $\mathrm{F}$ samples. The counts of probiotic cells in these types of mayonnaise were approximately $9.8 \times 10^{7}$ and $4 \times 10^{9}$ (CFU/g), respectively. All experiment was conducted in triplicate. 
Citation: Bigdelian E, Razavi SH (2014) Evaluation of Survival Rate and Physicochemical Properties of Encapsulated Bacteria in Alginate and Resistant Starch in Mayonnaise Sauce. J Bioprocess Biotech 4: 166 doi: 10.4172/2155-9821.1000166

Page 3 of 8

\section{Chemical and physical analysis}

The $\mathrm{pH}$ of the mayonnaise was measured using a digital $\mathrm{pH}$-meter (Microprocessor $\mathrm{pH}$-meter,). Titratable acidity was determined using the following formula at milli moles per 100 grams [24].

Equation 1: $W=V \times 0.9 / M$

$W=$ acidity at mill moles per 100 grams

$V=$ milliliters of consumed soda

$M=$ sample weight (preferably $100 \mathrm{~g}$ )

All chemical measurements were done in triplicate.

\section{Reaction of alginate without borate}

One $\mathrm{ml}$ of concentrated sulphuric acid and $0.1 \mathrm{ml}$ of $0.5 \mathrm{~g} / \mathrm{l}$ of alginate solution sample were taken in the test tube. The test tube was cooled in the ice bath and the mixture was shaken and kept in the water bath at $55^{\circ} \mathrm{C}$. After $30 \mathrm{~min}$, the sample was cooled in ice bath and $30 \mu \mathrm{l}$ of carbazole reagent $(0.1 \%$ in ethanol) was added. The tube was allowed to stand for about $3 \mathrm{~h}$ and then the absorbance was taken at $546 \mathrm{~nm}$. The color was stable for $2 \mathrm{~h}$.

\section{Rheology analysis}

The rheological measurements were evaluated using Brookfield rotational viscometer (DVIII) equipped by ULA. Obtained data analyzed by rheocalc 3.2 software, to determine its rheological properties. The temperature of the test $\left(25 \pm 0.1^{\circ} \mathrm{C}\right)$ was kept circulating-refrigerating water bath TC502 made by Brookfield Company.

\section{Statistical analysis}

The collected data was analyzed by SPSS statistics software, Version 18 edition .The mean values and the standard error were calculated from the data obtained with triplicate trials. These data were then compared by the Duncan's multiple range method.

\section{Result and Discussion}

\section{PH changes during mayonnaise sauces storage}

The $\mathrm{pH}$ changes during mayonnaise sauce storage in experimental mayonnaise sauces during storage at $5^{\circ} \mathrm{C}$ (per 7-day intervals has been presented) for a period of 91days are shown in Figures 1 and 2.

The $\mathrm{pH}$ changes (at end of 91 days storage) of mayonnaise sauces with encapsulated probiotic bacteria was lesser than the mayonnaise sauces inoculated with free probiotic bacteria, also the mayonnaise sauces containing encapsulated cells with Hi maize-alginate in both of L. casei and L. acidophilus samples had the minimum of $\mathrm{pH}$ changes during storage times.

Therefore $\mathrm{pH}$ decreasing in symbiotic mayonnaise samples containing L. acidophilus in Free states was about 0.3 and in samples containing encapsulated bacterial cells in $\mathrm{Hi}$ maize and alginate mixture and encapsulated in alginate $4 \%$ were about 0.1 and 0.244 unit respectively. Also $L$. casei inoculated in symbiotic mayonnaise samples in un-encapsulated forms, decreased $\mathrm{pH}$ about 0.3579 and bacterial cells in encapsulated with $\mathrm{Hi}$ maize and alginate mixture and encapsulated in alginate $4 \%$ states were decreased the $\mathrm{pH}$ of their environments about 0.1 and 0.17 unit respectively.

Generally Probiotic bacteria are slow acid producers [25] hence changes of $\mathrm{pH}$ at storage period time in symbiotic mayonnaise sauces wasn't great.

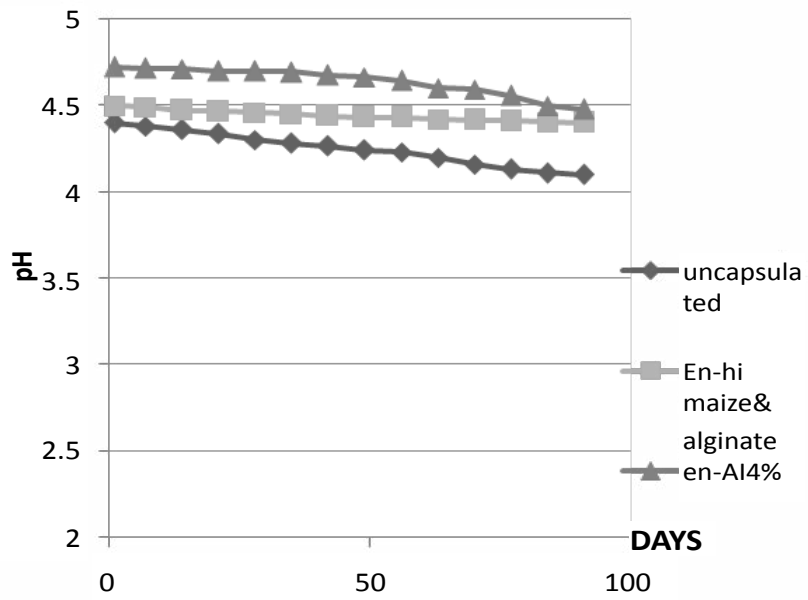

Figure 1: Mayonnaise sauces $\mathrm{pH}$ changes containing L.acidophilus in Free State, encapsulated by $\mathrm{Hi}$ maize-alginate and alginate $4 \%$ during storage.

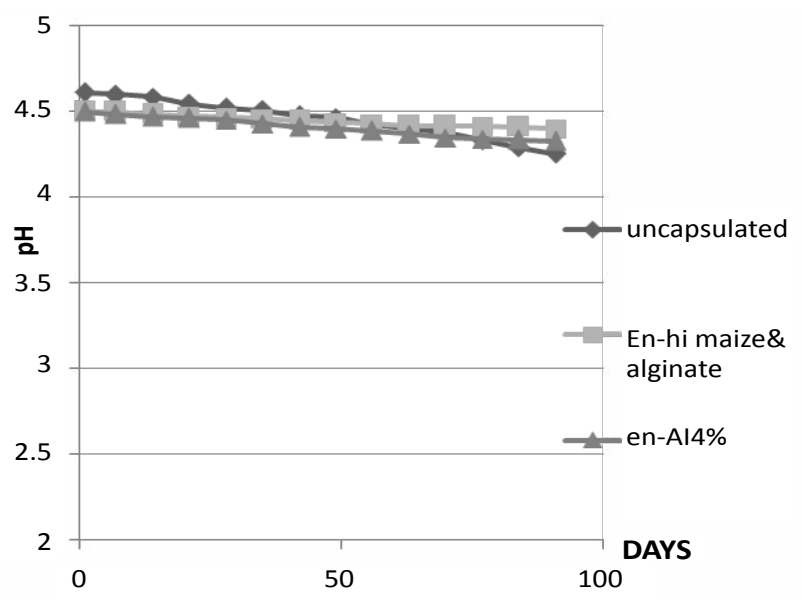

Figure 2: Mayonnaise sauces $\mathrm{pH}$ changes containing L.casei in Free State encapsulated by $\mathrm{Hi}$ maize-alginate and alginate $4 \%$ during storage.

\section{Producing acidity during mayonnaise storage}

Measuring the acidity per 7- day intervals (Figures 3 and 4) indicated parallel results that were reached about $\mathrm{pH}$ changes during 91 refrigerated in $4^{\circ} \mathrm{C}$. According these data's, increasing acidity in mayonnaise samples containing free $L$. acidophilus was approximately 0.25 and increasing acidity in samples containing encapsulated cells (similar strain) in Hi m aize and alginate mixture and sauces samples those blended with encapsulated cells in calcium alginate $4 \%$ were 0.142 and 0.21 respectively.

Also increasing acidity in mayonnaise samples containing L. casei in free, encapsulated with $\mathrm{Hi}$ maize-alginate and calcium alginate $4 \%$ were $0.14,0.1$ and 0.11 respectively.

As a result increasing of acidity from starting storage until 91 days in mayonnaise sauces those were containing encapsulated probiotic cells were less than free states, also the probiotic cells in Hi maizealginate coating is produced the minimum level of acidity in treatment containers in two kind of L. acidophilus and L. casei probiotic bacteria's. 


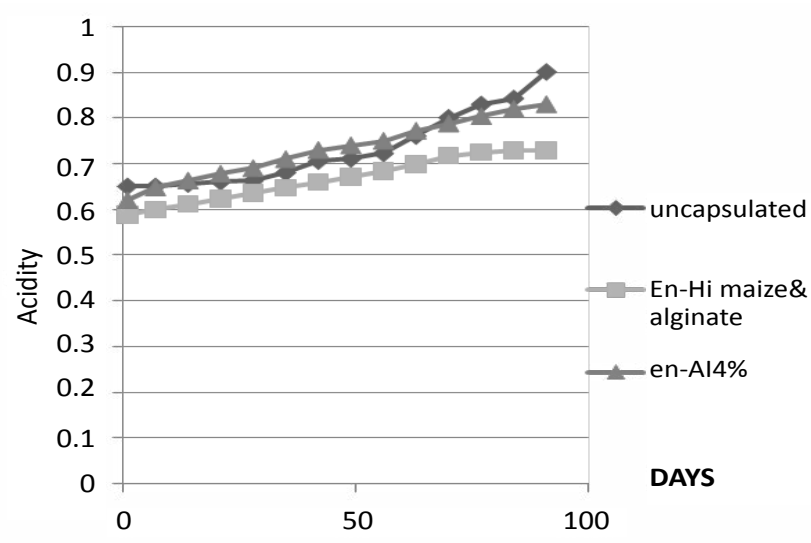

Figure 3: Mayonnaise sauces increasing acidity containing $L$. acidophilus in free and encapsulated states during storage.

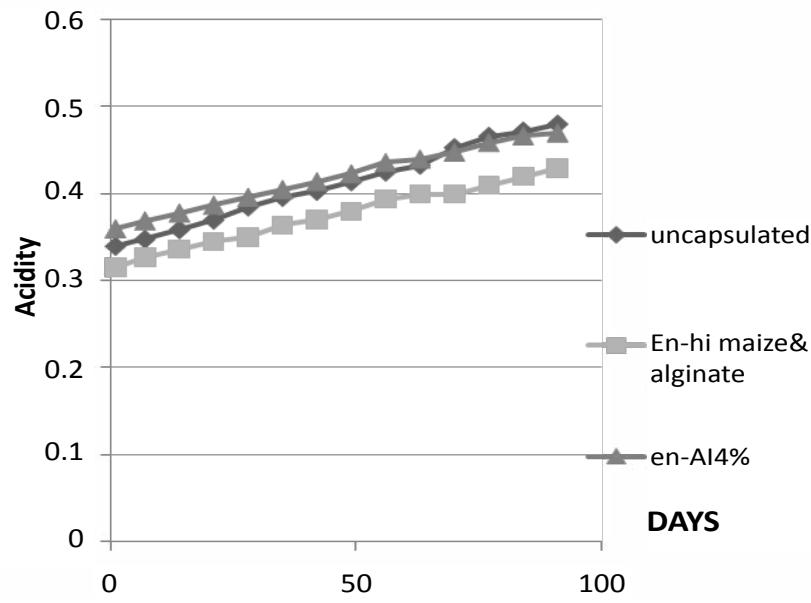

Figure 4: Mayonnaise sauces increasing acidity containing $L$. casei in free and encapsulated states during storage.

Therefore, microencapsulation of free cells greatly, but not completely, restricted their metabolic activity [26]. Even though symbiotic mayonnaise samples inoculated with $\mathrm{L}$. acidophilus had a little more acid producing compared with samples included L. casei bacterial cells.

\section{Survival of free and microencapsulated L. acidophilus \& L. case in mayonnaise sauce during storage time}

The effect of encapsulation with Hi-maize starch and alginate mixtures ( $2 \%$ concentration) and also by alginate ( $4 \%$ concentration) on the viability of probiotic microorganisms comparing with free cells in the mixture of mayonnaise sauces during 91 days of refrigerated storage period $\left(4^{\circ} \mathrm{C}\right)$ was investigated. Logarithmic numbers of surviving bacteria $(\log \mathrm{cfu} / \mathrm{mL})$ were measured at seven-day intervals are shown in the Table 1.

According to Table 1, viable cells of $L$. acidophilus mixture with mayonnaise sauce showed $2.659 \log$ decreases for the Free State after 91 days, while the encapsulated state with alginate ( $4 \%$ concentration) of the same strains showed a decrease of 1.48 logs. In the case of encapsulated bacteria (L. acidophilus) with Hi-maize starch and alginate mixtures, the cell numbers dropped substantially about 1.1497 $\log$ numbers by 91 days of storage at $4^{\circ} \mathrm{C}$. The loss of L. acidophilus showed significant differences $(\mathrm{P}<0.05)$ between the free and both type of encapsulated states in symbiotic mayonnaise sauce and there wasn't a significant difference between two type of encapsulated types, but as was observed, using the $\mathrm{Hi}$ maize starch along with alginate in micro beads cause improving 22.3 percentage the survival of $L$. acidophilus bacteria during storage period than usage alginate (4\%) lonely.

Sultana et al., [20], Homayouni et al., [8] and Mirzaei et al., [13], showed that using the Hi maize in encapsulation probiotics can significantly improving protection of viable bacterial counts in symbiotic ice cream and Iranian white brined cheese respectively $[7,12,19]$. The mayonnai se sauce samples that were contain of $L$. casei also showed the same results. In the case of free $L$. casei, the cell numbers dropped substantially about $2.52 \mathrm{log}$ numbers by 91 days of storage at $4^{\circ} \mathrm{C}$, however the decrease of the viable counts of encapsulated bacteria in Hi maze-alginate and encapsulated bacteria in alginate (4\%) were $1.1 \log$ and $1.377 \log$ respectively that indicates 20.11 percentage improving on survival of cells in the case of encapsulated with alginateHi maize comparing with cells coated with alginate $4 \%$.

There was a significant difference $(\mathrm{P}<0.05)$ between means of the counts of viable cells per 7-days intervals during storage time (91 days) in Free states of $L$. casei and both of encapsulated samples, however there wasn't observed any significant difference in comparison means of viable cells during storage time between $\mathrm{Hi}$ maize- alginate and alginate $4 \%$ encapsulated forms. These results indicate remarkable of increasing viability and resistance of probiotic cells by encapsulation against harsh environmental conditions at storage times.

Increasing cell stability of encapsulated probiotic bacteria with calcium alginate over the refrigerated storage time has been previously reported by Krasaekoopt, Kailasapathy and Mortazavian, that which are in agreement with the results obtained from present research [2729]. Also these data's again confirmed advantages of encapsulation of probiotic cells with $\mathrm{Hi}$ maize in combination with alginate that more than twice protection of viable counts of bacteria compared Free State caused. In addition, it was demonstrated that, encapsulated cells required longer time to decrease one log cycle in viable counts and encapsulated bacterial cells with alginate and resistant starch had the most slow rate of loss viable cell rate.

The supporting impact of microcapsules on probiotic bacteria arises from their barrier properties against the detrimental conditions of mayonnaise environment such as low $\mathrm{pH}$, organic acids and antibacterial effects of mustard [30] and the existence of some antibacterial enzymes' from albumen such as lysozyme, conalbumin and avidin.

Overall the problem of sensitivity to acidity of the probiotic culture is compounded by the fact that acidity may increase during storage, a phenomenon known as 'over acidification' [31]. Increasing rate of viability decline of free probiotic bacteria can be attributed to the adverse effects of accumulated organic acid molecules and hydrogen ions after they grew inside the mayonnaise environment at days 49 and 56 in L. acidophilus and L. casei respectively.

About encapsulated bacteria accumulating of organic acid molecules and hydrogen ions had a lower rate because of limitation accessibility to nutrients'. This fact is indicated by slower rates of $\mathrm{pH}$ drop and acidity increase during refrigeration of both encapsulated types of probiotic bacteria which caused a slower rate of viability decline comparing free probiotic bacteria cells. But the greater loss of survival of encapsulated L. acidophilus and $L$. casei cells at the end of 
Citation: Bigdelian E, Razavi SH (2014) Evaluation of Survival Rate and Physicochemical Properties of Encapsulated Bacteria in Alginate and Resistant Starch in Mayonnaise Sauce. J Bioprocess Biotech 4: 166 doi: 10.4172/2155-9821.1000166

Page 5 of 8

storage period time may be due to the gradually increased amount of organic acid molecules inside the capsules after slow diffusion through the capsules pores in mayonnaise environment.

This suggests that the starch grains were presented in the cavities in the alginate matrix [19] may could fulfill the shell surface of beads and due to more restriction of crossing nutrient and metabolites across shell matrix and also reduction of entrance organic acids and other adverse components (such as some antibacterial components of mustard or antibacterial enzymes' of albumen) exist in mayonnaise environment. In this regard, reduction of metabolic activity of probiotic cells in the case of coated cells with resistant starch and alginate caused to a very gentle increasing of acidity and so slowing loss of viable cells during refrigeration period.

With comparing two strains of probiotic cells, it was found that loss of all types of free and coated bacterial cells of L. casei from days 1 to 91th was lower than the same type of L. acidophilus cells. In this way the survival of bacteria against unfavorable conditions could be species dependent. This finding is in agreement with those of Haynes, Kailasapathy and Homayouni $[23,28]$.

\section{Comparing rheological properties of mayonnaise sauces before and after storage period}

The viscosity of Non-Newtonian fluids cannot be calculated using only the base properties, the main calculation should be in the flow model. In or-der to correlate flow model and medium model with the smallest change possible. Since the flow behavior index is only a function of the states of the fluid such as the temperature, it can be defined and calculated in the medium model. By adding this partial function for the definition of the flow behavior index in the base medium model, implementing the governing equations or tables for all the fluid models is made possible.

In case the fluid is a Newtonian fluid such as water, the flow behavior index should be set to the constant number of " 1 " and with decline of this index from " 1 " demonstrate fluid is nearing shearthinning properties [32,33].

In this work comparing consistency indexes and flow indexes of symbiotic mayonnaise sauces before and after period of storage time were studied.

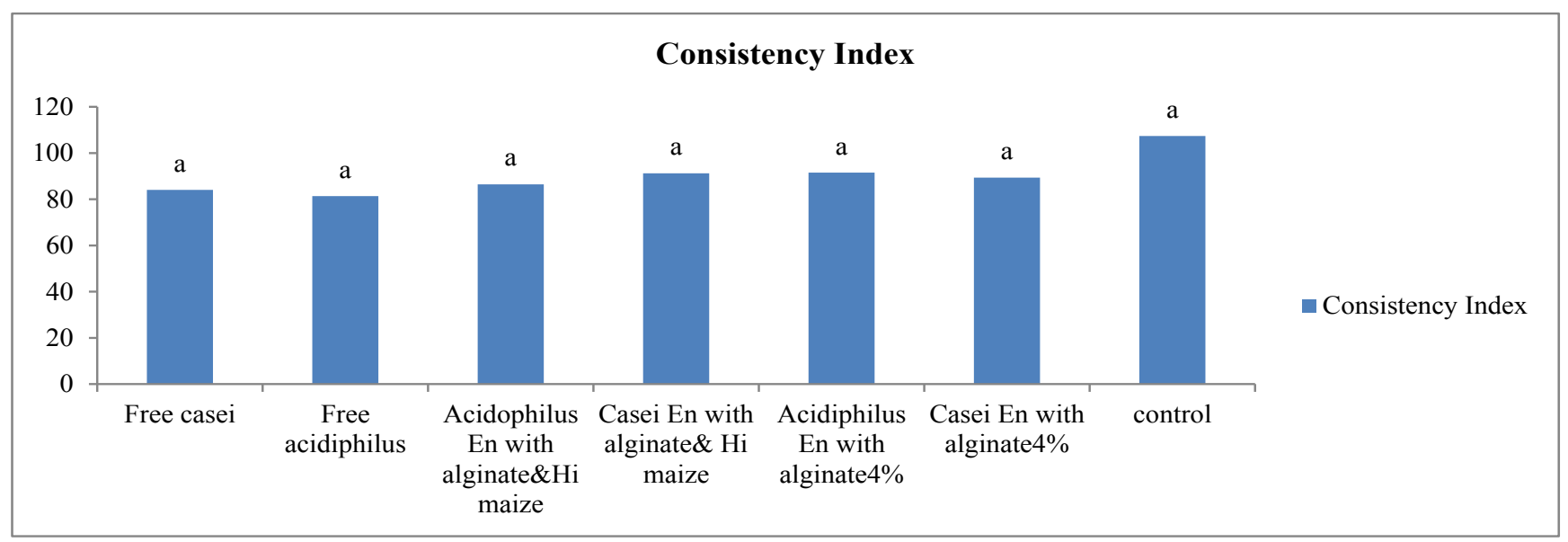

Figure 5: Consistency indexes were compared by the Duncan's multiple range method at the start of storage time $(p<0.05)$.

\section{Flow Index}

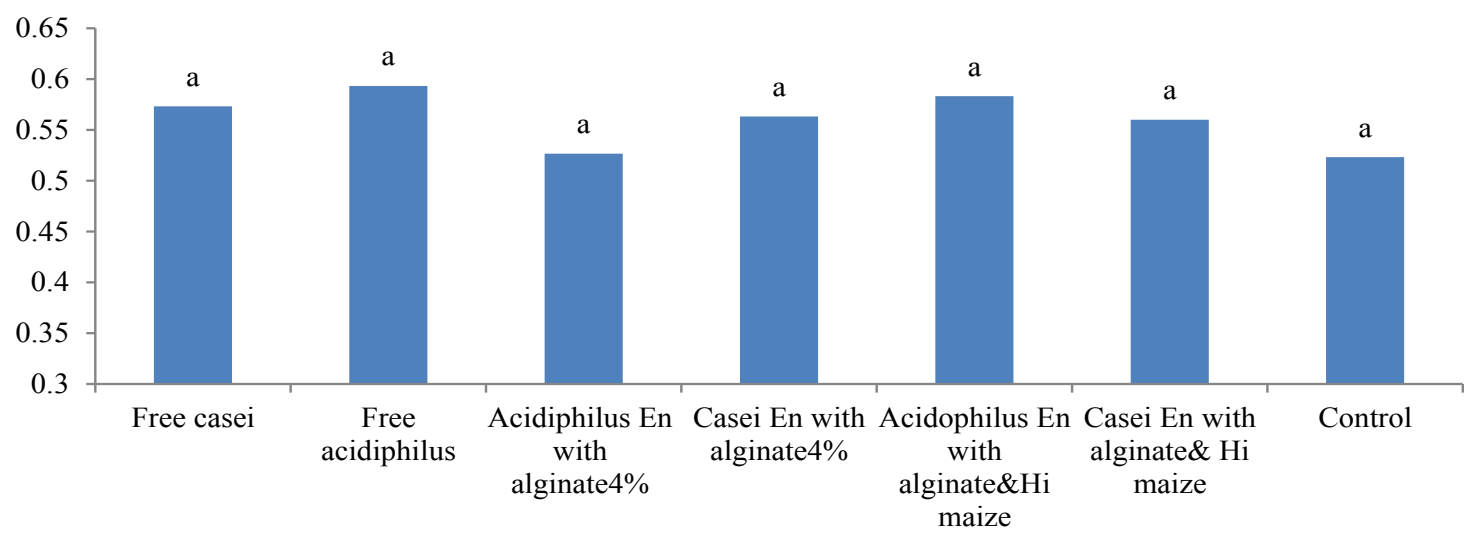

Flow Index

Figure 6: Flow indexes were compared by the Duncan's multiple range method at the start of storage time $(p<0.05)$. 
According Figure 5 consistency indexes of symbiotic mayonnaise sauces in neither samples at the start of storage period hadn't significant difference $(\mathrm{p}<0.05)$ with control treatments (control samples hadn't any probiotic cells) and this fact indicates that adding free probiotic cells or encapsulation operation hadn't significant changes in rheological properties of mayonnaise sauce.

This fact proved while it wasn't any significant differences $(\mathrm{p}<0.05)$ between flow indexes of control and symbiotic mayonnaise sauces in both free and encapsulated probiotic cell samples (both of $L$. casei and L. acidophilus) at the start of storage period (Figure 6).

So there weren't significant changes in rheological properties' of our symbiotic product by inoculation of probiotic cells in free or encapsulated form in mayonnaise sauces samples (Figure 7).

After 91 days storage period rheological properties of symbiotic mayonnaise sauces samples were measured and compared with control samples to determine any changes in consistency indexes and flow indexes.

The results (Figures 8 and 9) indicated that the consistency indexes in control samples and symbiotic mayonnaise sauces containing encapsulated probiotic bacteria's (both $L$. casei and L. acidophilus in two kinds of beads) were not any statistical significant difference

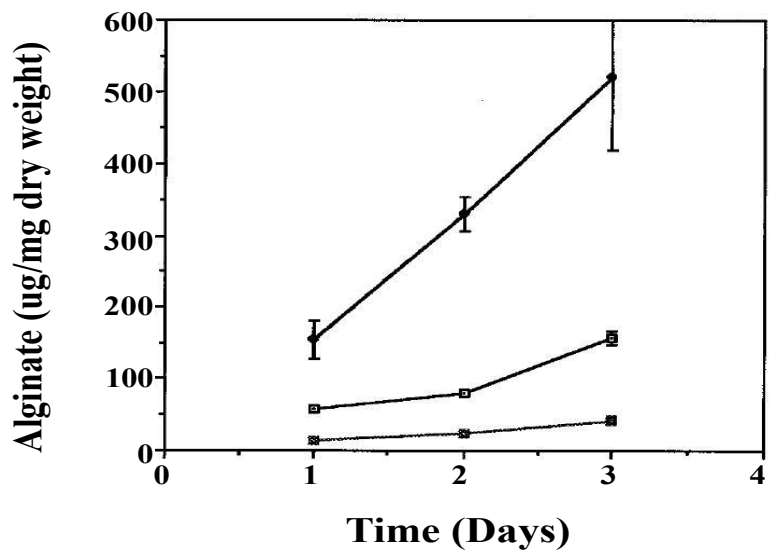

Figure 7: Alginate production $(\mathrm{p}<0.05)$. But all symbiotic mayonnaise samples containing free cells (of both species) had a significant differences $(\mathrm{p}<0.05)$ in consistency indexes compared with control mayonnaise samples, however there were not any significant differences between mayonnaise samples containing encapsulated bacteria and samples containing free cells (both species in two kinds of beads) in consistency indexes .

About flow index, after period of storage time there weren't significant differences $(\mathrm{p}<0.05)$ between control samples and samples containing encapsulated probiotics (both strains, both coating) but we had significant differences $(\mathrm{p}<0.05)$ in flow indexes of control samples and mayonnaise containing free cells (both strains). In other wise we saw significant differences $(\mathrm{p}<0.05)$ in flow indexes neither of samples containing free $L$. acidophilus and samples containing encapsulated cells though nor about samples containing free L. casei cells.

Thus after 91 days storage period we didn't see significant changes in rheological properties of encapsulated probiotic mayonnaise samples (Figure 7).

\section{Conclusion}

In this study we proved that mayonnaise sauce could be serving as carriers for delivering the probiotic bacteria into the human gut. Also this work demonstrated that microencapsulation of probiotic bacteria significantly and noticeably improves their viability in mayonnaise sauce throughout the 91 days refrigerated storage at $4^{\circ} \mathrm{C}$.

The high total solids level in mayonnaise sauce including the oil and egg solids may provide protection for the probiotic bacteria. A modified method of encapsulation has been reported in this study. There appears to be much potential for using the prebiotic resistant starch with alginate during encapsulation since it does enhance the survival of the probiotic bacteria.

According to the results of this study, microencapsulation of $L$. acidophilus and $L$. casei cells with calcium alginate gel and resistant starch can successfully keep the count of this probiotic bacterium higher than encapsulated cells of them with calcium alginate $4 \%$, but enough in both methods for the therapeutic minimum in the mayonnaise sauce [34].

So at the end of 91 days of storage, the number of viable probiotic

\section{Consistency Index}

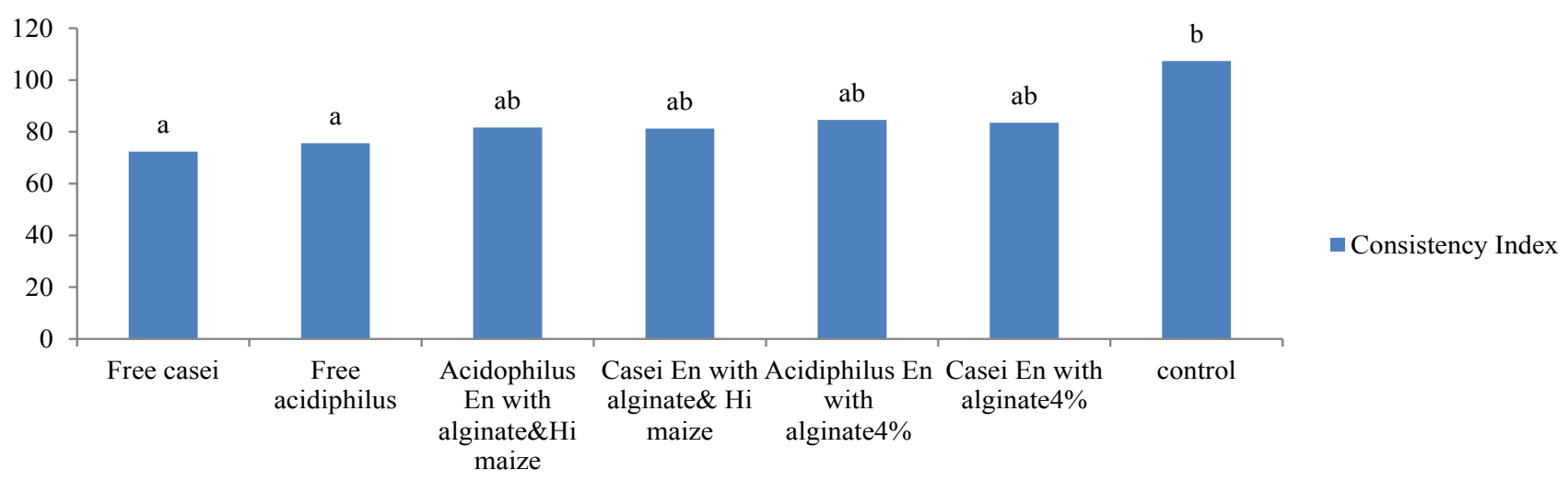

Figure 8: Consistency indexes were compared by the Duncan's multiple range method at the end of storage time $(p<0.05)$. 


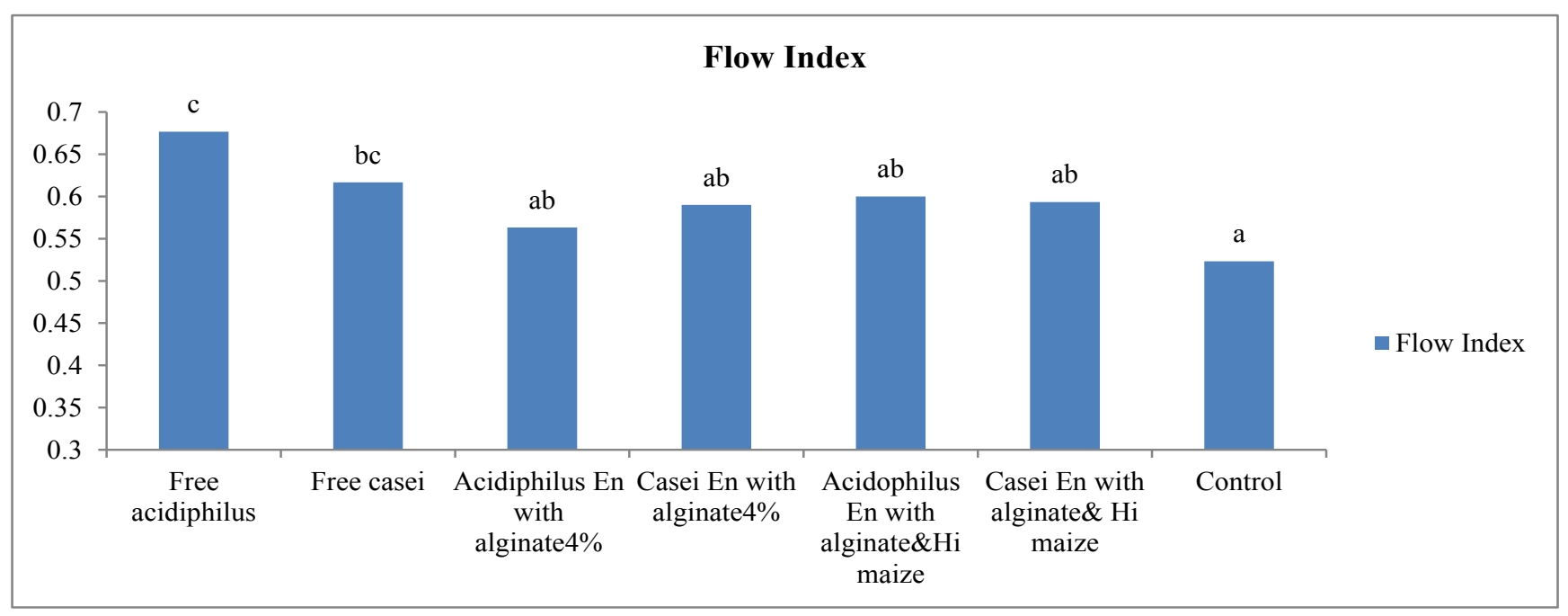

Figure 9: Flow indexes were compared by the Duncan's multiple range method at the end of storage time $(p<0.05)$.

\begin{tabular}{|c|c|c|c|c|c|c|}
\hline \multirow[t]{2}{*}{ Days } & \multicolumn{3}{|c|}{ L.acidophilus } & \multicolumn{3}{|c|}{ L.casei } \\
\hline & Free & En-Hi\&AL ${ }^{a}$ & En-AL4\% ${ }^{b}$ & Free & En-Hi\&AL ${ }^{a}$ & En-Al4\% ${ }^{b}$ \\
\hline 0 & 8.698 & 9.601 & 9.42 & 8.748 & 8.301 & 8.477 \\
\hline 7 & 8.6 & 9.3 & 9.397 & 8 & 8.278 & 8.384 \\
\hline 14 & 8.505 & 9.1 & 9.389 & 7.778 & 8.146 & 8.291 \\
\hline 21 & 8.468 & 8.9 & 9.318 & 7.568 & 8.1 & 8.198 \\
\hline 28 & 8.451 & 8.85 & 9.24 & 7.477 & 8.079 & 8.105 \\
\hline 35 & 8.301 & 8.82 & 9.113 & 7.486 & 7.994 & 8 \\
\hline 42 & 8 & 8.77 & 8.845 & 7.409 & 7.929 & 7.919 \\
\hline 49 & 7.9 & 8.7 & 8.654 & 7.358 & 7.845 & 7.786 \\
\hline 56 & 7.568 & 8.66 & 8.397 & 7.278 & 7.69 & 7.733 \\
\hline 63 & 7.185 & 8.602 & 8.38 & 7.146 & 7.582 & 7.6 \\
\hline 70 & 6.948 & 8.54 & 8.25 & 7.095 & 7.462 & 7.337 \\
\hline 77 & 6.711 & 8.486 & 8.11 & 6.845 & 7.304 & 7.284 \\
\hline 84 & 6.474 & 8.47 & 8 & 6.544 & 7.227 & 7.22 \\
\hline 91 & 6.039 & 8.45 & 7.94 & 6.23 & 7.204 & 7.1 \\
\hline
\end{tabular}

a: Encapsulated by $\mathrm{Hi}$ maize starch and Calcium alginate $(2 \%$ concentrations $)$

b: Encapsulated by Calcium alginate (4\%concentrations)

Table 1: Viability of probiotic bacteria (log cfu/mL) in encapsulated and un-encapsulated treatments over a 91 -dayrefrigerated storage period $\left(4^{\circ} \mathrm{C}\right)$, per 7 -day intervals.

bacteria in mayonnaise types containing L. acidophilus and L. casei that encapsulated (with Hi maize-alginate and alginate 4\%) were higher than what was recommended by the International Dairy Federation (107 CFU/g) (Table 1).

The addition of probiotic cultures in encapsulated forms tend to slow down the post acidification during storage of mayonnaise sauces. Thus according our views encapsulation led to limitation accessibility of probiotic bacterial cells to consuming nutrients and caused to restriction to increasing acidity and $\mathrm{pH}$ changing comparing the Free State probiotic cells in mayonnaise sauces samples during storage period [35].

The $\mathrm{pH}$ changing and increasing of acidity in symbiotic mayonnaise samples containing L. acidophilus and $L$. casei encapsulated with $\mathrm{Hi}$ maize and alginate were less than mayonnaise samples that contained encapsulated cells with calcium alginate $4 \%$ but we 've seen the most changing in acidity and $\mathrm{pH}$ in samples contains free cells (in both kind of probiotic bacteria's). This may be due to the slower uptake of nutrients and the slow release of metabolites across the encapsulated alginate shell and particularly in beads those filled with resistant starch particles [19].

Also about rheological changes in symbiotic mayonnaise sauces it's defined that inclusion of probiotic cells in free or coated states couldn't have a significant effect on consistency and flow indexes of mayonnaise sauces but after the period of storage the high ratio of increasing acidity and producing more of other metabolites in mayonnaise containing free probiotic cells (L. casei \& L. acidophilus) comparing with control samples we had a significant changes in flow and consistency indexes and these samples hadn't initial textures.

Even though by the microencapsulation of probiotic cells additional of biological and chemical properties, we could save rheological (flow and consistency indexes) qualities' of symbiotic mayonnaise sauces and so there weren't significant changes in these factors comparing control treatment's after 91 days storage period. 
Citation: Bigdelian E, Razavi SH (2014) Evaluation of Survival Rate and Physicochemical Properties of Encapsulated Bacteria in Alginate and Resistant Starch in Mayonnaise Sauce. J Bioprocess Biotech 4: 166 doi: 10.4172/2155-9821.1000166

Page 8 of 8

According these results, microencapsulation with alginate gel and resistant starch had the best efficiency to survival the probiotic cells enough for therapeutic effects and as well as increasing storage time with less chemical changes in symbiotic mayonnaise sauce during refrigerate in $4^{\circ} \mathrm{C}$.

Alginates have a clear antibacterial effect as evidenced by the reduction in growth following the addition of alginates. This inhibitory effect of alginates on bacterial growth was found to be bacteriostatic as the cultures grew well when plated onto agar. The bacteriostatic effect is likely in part to be due to the iron Alginates have a clear antibacterial effect as evidenced by the reduction in growth following the addition of alginates. This inhibitory effect of alginates on bacterial growth was found to be bacteriostatic as the cultures grew well when plated onto agar. The bacteriostatic effect is likely in part to be due to the iron chelating capabilities of alginates as the antibacterial effect was lost when the MIC assay was repeated using alginates loaded with iron. Thus in summary we provide evidence that it is likely that alginates mediate these alterations in the gut micro flora through their potential to sequester iron.

Further studies are needed to evaluate the protection effect of microencapsulation on the probiotic survival in the gastrointestinal tract.

\section{References}

1. Cruz AG, Antunes AEC, Sousa ALOP, Faria JAF, Saad SMI (2009) Review Icecream as a probiotic food carrier. Food Research International 42: 1233-1239.

2. Muthukumarasamy P, Holley RA (2006) Microbiological and sensory quality of dry fermented sausages containing alginate-microencapsulated Lactobacillus reuteri. International Journal of Food Microbiology 111: 164-169.

3. www.fao.org/es/ESN/Probio/Probio.htm

4. Possemiers S, Marzorati M, Verstraete W, Van de Wiele T (2010) Bacteria and chocolate: A successful combination for probiotic delivery. International Journal of Food Microbiology 141: 97-103.

5. Chan ES, Zhang Z (2002) Encapsulation of probiotic bacteria Lactobacillus acidophilus by direct Compression. Institution of Chemical Engineers 80: 78-82.

6. Brinques GB, Ayub M (2011) Effect of microencapsulation on survival of Lactobacillus plantarum in simulated gastrointestinal conditions, refrigeration, and yogurt. Journal of Food Engineering 103: 123-128.

7. Mohammadi N, Ahari H, Fahimdanesh M, Khosravi Zanjani MA, Anvar A, et al., (2013) Survival of alginate-prebiotic microencapsulated Lactobacillus acidophilus in mayonnaise sauce. Iranian Journal of Veterinary Medicine 6: 259-264.

8. Homayouni A, Azizi A, Ehsani MR, Yarmand MS, Razavi SH (2008) Effect of microencapsulation and resistant starch on the probiotic survival and sensory properties of synbiotic ice cream. Food Chemistry 111: 50-55.

9. Mandal S, Puniya AK, Singh K (2006) Effect of alginate concentrations on survival of microencapsulated Lactobacillus casei NCDC-298. International Dairy Journal 16: 1190-1195.

10. Chávarri M, Marañón I, Ares R, Ibáñez FC, Marzo F, et al., (2010) Microencapsulation of a probiotic and prebiotic in alginate-chitosan capsules improves survival in simulated gastro-intestinal conditions. International Journal of Food Microbiology 142: 185-189.

11. Gibson GR, Probert HM, Van Loo J, Rastall RA, Roberfroid MB (2004) Dietary modulation of the human colonic microbiota: updating the concept of prebiotics. Nutr Res Rev 17: 259-275.

12. Homayouni A, Ehsani MR, Azizi A, Razavi SH, Yarmand MS (2007) An introduction to functional dairy foods. In Proceedings of the First National Functional Food Congress: 60.

13. Mirzaei $\mathrm{H}$, Pourjafar $\mathrm{H}$, Homayouni A (2012) Effect of calcium alginate and resistant starch microencapsulation on the survival rate of Lactobacillus acidophilus La5 and sensory properties in Iranian white brined cheese. Food Chemistry 132: 1966-1970.

14. Ross RP, Fitzgerald GF, Collins JK, Stanton C (2002) Cheese delivering biocultures - probiotic cheese. The Australian Journal of Dairy Technology 57 71-78.

15. Ranadheera RDCS, Baines SK, Adams SK (2010) Importance of food in probiotic efficacy. Food Research International 43: 1-7.

16. Liua H, Xu XM (2007) Rheological, texture and sensory properties of low-fat mayonnaise with different fat mimetics. LWT 40: 946-954

17. Shen R, Luo S, Dong J (2011) Application of oat dextrine for fat substitute in mayonnaise. Food Chemistry 126: 65-71.

18. Kailasapathy K, Chin J (2000) Survival and therapeutic potential of probiotic organisms with reference to Lactobacillus acidophilus and Bifidobacterium spp. Immunology \& Cell Biology 78: 80-88.

19. Shah NP (2000) Probiotic bacteria: Selective enumeration and survival in dairy foods. Journal of Dairy Science 83: 894-907.

20. Sultana K, Godward G, Reynolds N, Arumugaswamy R, Peiris P, et al. (2000) Encapsulation of probiotic bacteria with alginate-starch and evaluation of survival in simulated gastrointestinal conditions and in yoghurt. International Journal of Food Microbiology 62: 47-55.

21. Fahimdanesh M, Mohammadi N, Ahari H, Khosravi MA, Zanjani FZH, et al. (2012) Effect of microencapsulation plus resistant starch on survival of Lactobacillus casei and Bifidobacterium bifidum in mayonnaise sauce. African Journal of Microbiology Research 6: 6853-6858

22. Vinderola CG, Prosello W, Ghiberto D, Reinheimer JA (2000) Viability of probiotic (Bifidobacterium, Lactobacillus acidophilus and Lactobacillus casei) and nonprobiotic microflora in Argentinean Fresco cheese. Journal of Dairy Science 83: 1905-1911.

23. Haynes IN, Playne MJ (2002) Survival of probiotic cultures in low fat ice cream Australian Journal of Dairy Technology 57: 10-14.

24. Sheu TY, Marshall RT (1993) Microencapsulation of Lactobacilli in calcium alginate gels. Journal of Food Science 54: 557-561.

25. Chen MB (2005) Study on processing technology of functional mayonnaise with plasma cholesterol lowering activity. Academic Periodical of Farm Products Processing 32: 22-24.

26. ISIRI number 5222 (2000) Institute of Standards and Industrial Research of Iran. Yoghurt - determination of total Titratable Acidity - potentiometric method, Tehran, Iran

27. Krasaekoopt W, Bhandari B, Deeth $\mathrm{H}$ (2004) The influence of coating materials on some properties of alginate beads and survivability of microencapsulated probiotic bacteria. International Dairy Journal 14: 737-743.

28. Kailasapathy K, Masondole $L$ (2005) Survival of free and microencapsulated Lactobacillus acidophilus and Bifidobacterium lactis and thei effect on texture of feta cheese. Australian Journal of Dairy Technology 60: 252-258.

29. Mortazavian AM, Ehsani MR, Azizi A, Razavi SH, Mousavi SM, et al. (2008) Effect of microencapsulation of probiotic bacteria with calcium alginate on cell stability during the refrigerated storage period in the Iranian yogurt drink (Doogh). MILCAD 63: 233-348.

30. Marshall VM, Tamime AY (1997) Starter cultures employed in the manufacture of biofermented milks. International Dairy Journal 50: 35-39.

31. Adeli milani M, Mizani M, Gavami M (2010) Effects of yellow mustard powder on microbial population, $\mathrm{pH}$ and organoleptic properties of mayonnaise. Iranian Journal of Nutrition Sciences \& Food Technology 5: 35-44.

32. Kailasapathy K (2006) Survival of free and encapsulated probiotic bacteria and their effect on the sensory properties of yoghurt. LWT 39: 1221-1227.

33. Kailasapathy K, Sultana k (2003) Survival and b-D galactosidase activity of encapsulated and free Lactobacillus acidophilus and Bifidobacterium lactis in ice cream. Australian Journal of Dairy Technology 58: 223-227.

34. Jahangiri P, Streblow R, Müller D (2012) Simulation of Non-Newtonian Fluids using Modelica. Proceedings of the 9th International Modelica Conference: 57-60.

35. Tang HS, Kalyon DM (2004) Estimation of the parameters of HerschelBulkley fluid under wall slip using a combination of capillary and squeeze flow viscometers. Rheologica Acta 43: 80-88. 